Paper ID \#18998

\title{
Longitudinal Effects of the Foundation Coalition Curriculum on Chemical and Petroleum Engineering Student Performance
}

\section{Dr. So Yoon Yoon, Texas A\&M University}

So Yoon Yoon, Ph.D., is an assistant research scientist at the Institute for Engineering Education and Innovation (IEEI) within the College of Engineering, Texas A\&M University and the Texas A\&M Engineering Experiment Station (TEES). She received her Ph.D. in Educational Psychology with specialties in Gifted Education and her M.S.Ed. in Educational Psychology with specialties in Research Methods and Measurement both from Purdue University. Her work centers on P-16 STEM education research with a focus on engineering as a psychometrician, program evaluator, and institutional data analyst. She has authored/co-authored more than 40 journal articles and conference proceedings and served as a reviewer of journals in engineering education, STEM education, and educational psychology, as well as an external evaluator and an advisory board member on several NSF-funded projects.

\section{Dr. Mark T. Holtzapple, Texas A\&M University}

Mark Holtzapple received his chemical engineering degrees from Cornell University (BS, 1978) and the University of Pennsylvania (PhD, 1981). After his formal education, he served as a captain in the US Army Natick R\&D Center and worked on a miniature air conditioner for soldiers wearing chemical protective clothing. In 1986, he joined the faculty in the Department of Chemical Engineering at Texas A\&M University. He has received many awards for teaching and research, including the Presidential Green Chemistry Challenge Award from the president and vice president of the United States. His research focuses on sustainability including conversion of waste biomass to fuels, chemicals, and animal feed; high-efficiency engines and air conditioners; conversion of waste heat to electricity; high-torque electric motors; and water desalination.

\section{Dr. Bonnie J. Dunbar Ph.D., Texas A\&M University}

Professor Bonnie J. Dunbar, PhD NAE RSEcorr

TEES Distinguished Research Professor Department of Aerospace Engineering Director, Institute for Engineering Education Innovation (IEEI) Texas A\&M University, College Station, TX

Dr. Dunbar is a retired NASA astronaut, engineer and educator, currently with Texas A\&M Engineering as a Texas A\&M Engineering Experiment Station (TEES) Distinguished Research Professor in the Department of Aerospace Engineering. She also has a joint appointment as the Director of the TEES Institute for Engineering Education and Innovation (IEEI). Dunbar, who is a member of the prestigious National Academy of Engineering, came to Texas A\&M from the University of Houston where she was an M.D. Anderson Professor of Mechanical Engineering. There she provided leadership in the development of a new integrated university science, technology, engineering and mathematics (STEM) center and was Director of the Science and Engineering Fair of Houston. She also directed the SICSA Space Architecture and Aerospace graduate programs. She has devoted her life to furthering engineering, engineering education, and the pursuit of human space exploration. Dunbar worked for The Rockwell International Space Division Company building Space Shuttle Columbia and worked for 27 years at NASA, first as a flight controller; then as a mission specialist astronaut, where she flew five space shuttle flights, logging more than 50 days in space; and then served for 7 years as a member of the Senior Executive Service (SES). Her executive service included assistant NASA JSC director for university research; deputy director for Flight Crew Operations; Associate Director for ISS Mission Operations development, and as NASA headquarters deputy associate administrator for the Office of Life and Microgravity Sciences and Applications (OLMSA). After retiring from NASA, Dunbar became president and CEO of The Museum of Flight in Seattle, where she established a new Space Gallery and expanded its K12 STEM educational offerings. She has also consulted in aerospace and STEM education as the president of Dunbar International LLC, and is an internationally known public speaker. Dunbar holds bachelor and master degrees in ceramic engineering from the University of Washington and a Ph.D. in mechanical/biomedical engineering from 
the University of Houston. She is a Fellow of the American Ceramic Society, the American Institute of Aeronautics and Astronautics, and the Royal Aeronautical Society. She has been awarded the NASA Space Flight Medal five times, the NASA Exceptional Leadership Medal and the NASA Distinguished Service Medal. Dunbar was inducted into the Royal Society of Edinburgh, and in 2002 was elected to the US National Academy of Engineering. In 2013 she was selected into the Astronaut Hall of Fame and is currently the President of the international Association of Space Explorers. 


\title{
Longitudinal Effects of the Foundation Coalition Curriculum on Chemical and Petroleum Engineering Student Performance
}

\begin{abstract}
This Complete Research explores the longitudinal effects of the Foundation Coalition (FC) curriculum on chemical and petroleum engineering student graduation outcomes: retention, timeto-graduation, and cumulative GPA. In 1993, a large southwest public university joined the FC, a 10-year multi-university NSF initiative to improve first-year engineering (FYE) education. After pilot classes were developed, in 1998 the FC curriculum was implemented college-wide. In 2003, the university adopted a track system with the FYE foundational courses separated into three tracks: Track A (aerospace, agricultural, biomedical, civil, industrial, mechanical, and nuclear engineering), Track B (computer and electrical engineering), and Track C (chemical and petroleum engineering). Track A was primarily project-based and used Mindstorms, Legos, magnetic balls, and beams to build structures. Track B focused on circuit design and computer programming. Only Track C maintained the FC curriculum until 2013. The target population of this study is first-time-in-college (FTIC) chemical or petroleum engineering students who started in summer or fall during the 2005 to 2007 school year and took Track A (339 students) or Track C (256 students). There was no statistically significant difference in retention. Although Track C students graduated in engineering 0.18 semesters quicker than Track A students, the differences were not statistically significant. However, there was a statistically significant difference in the cumulative GPAs when they graduated in engineering: Track $\mathrm{C}$ students' average cumulative GPA (3.27) was significantly higher than Track A students (3.16).
\end{abstract}

\section{Introduction}

\section{A. Background}

In 1993, a large southwest public university joined the Foundation Coalition (FC), a 10-year multi-university NSF initiative to improve first-year engineering (FYE) education (Clark, Froyd, Merton, \& Richardson, 2003; Cordes, Evans, Frair, \& Froyd, 1999; Fournier-Bonilla, Watson, \& Malavé, 2000; Holtzapple, Toback, \& Holtzapple, 2014). Pilot classes were developed, refined, and evaluated for years (Al-Holou et al., 1999; Barrow et al., 1995). Finally, in 1998, the FC curriculum for two engineering foundational courses for one school year was scaled up and implemented as part of the FYE common curriculum at the large southwest public university (Fournier-Bonilla, Watson, \& Malavé, 2000; Fournier-Bonilla, Watson, Malavé, \& Froyd, 2001). The courses were team-taught by two instructors, one drawn from the engineering departments and one from the graphics faculty.

Later, a "barter" system was developed where each department was obligated to assign faculty to the course. In some cases, departments took this obligation seriously and assigned dedicated faculty. In other cases, there was minimal commitment; sometimes, graduate students were assigned to teach the class. The course was pretty broad and had the following issues: (a) some 
faculty did not feel comfortable teaching material outside their major; and (b) some faculty felt it was a waste of time to teach topics that did not directly impact their students.

In 2003, the course was separated into three tracks: (a) Track A for aerospace, agricultural, biomedical, civil, industrial, mechanical, and nuclear engineering majors, (b) Track B for computer and electrical engineering majors, and (c) Track $\mathbf{C}$ for chemical and petroleum engineering majors. Track A was primarily project-based and used Mindstorms, Legos, magnetic balls, and beams to build structures. This track benefited from additional NSF funding designed to improve the FYE education (Froyd \& Ohland, 2005). Track B focused on circuit design and computer programming. Only Track $\mathrm{C}$ maintained the $\mathrm{FC}$ curriculum and continued to refine it. For ten years (2003 to 2013), the FYE students at the university were taught in three tracks (Holtzapple, Toback, \& Holtzapple, 2014).

\section{B. The Foundation Coalition Curriculum}

From 1993 to 2004 when the National Science Foundation (NSF) funded the Foundation Coalition (FC) to reform and improve the education of freshmen engineers, the FC curriculum included the following four themes: integrated curriculum, active/cooperative learning, technology-enabled learning, and continuous improvement (Morgan \& Bolton, 1998; Froyd \& Ohland, 2005).

Integrated curriculum. The FC curriculum is designed to integrate with both the freshman and upperclassman years. To support the freshman year, the curriculum reinforces physics, chemistry, and mathematics. To support the upperclassman years, the curriculum includes foundational topics, such as thermodynamics, rate processes (e.g., fluids, heat transfer, and electricity), and "engineering accounting," which is discussed later. A detailed description of the two engineering foundational course content is provided in Table 1.

Active/cooperative learning. Students are organized into teams of three to four. Lectures are interspersed with frequent group activities, such as calculating the answer to a problem, discussing various options to arrive at a consensus answer, brainstorming, and working on projects.

Technology-enabled learning. In the classroom, students have their own computer equipped with standard Office software (e.g., Word, Excel) as well as specialized engineering software (e.g., AutoCAD, Inventor). The computers are connected to the internet so students can access the web.

Continuous improvement. The FC course is constantly evaluated to update the content and to improve content delivery.

In addition to the above themes, the FC at the university included the following: (a) clustering of students into "learning communities" who took common courses (math, engineering, science); (b) using student teams both inside and outside the classroom; (c) industry involvement in the classroom; (d) undergraduate peer teachers; and (e) faculty team teaching. 


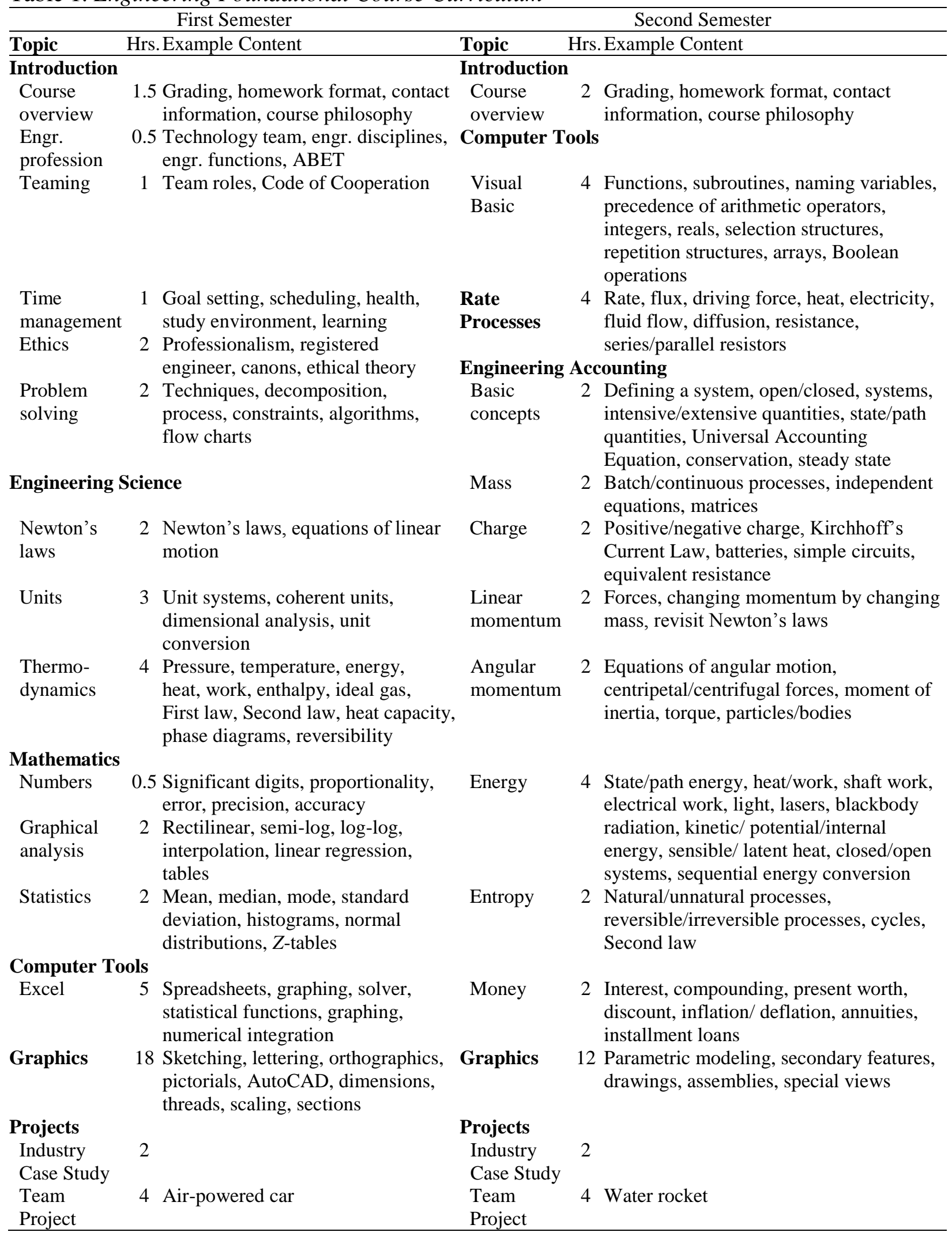

Note. Hrs. $=$ Hours 


\section{Engineering Accounting}

Engineering accounting is the most important concept taught in the second semester of the FC curriculum. It is a unifying framework that applies to all engineering disciplines; in fact, engineering disciplines can be distinguished by what they count (Table 2). Here, engineering accounting can only be applied to extensive quantities (e.g., mass, volume, charge, momentum), which depend upon scale. Engineering accounting cannot be applied to intensive quantities (e.g., temperature, pressure, concentration, voltage), which do not depend upon scale. If all engineers are taught the engineering accounting framework, it is much easier for them to work on interdisciplinary projects because they have a common language.

Table 2. Engineering Disciplines Defined by What They Count

\begin{tabular}{lccccccc}
\hline $\begin{array}{c}\text { Engineering } \\
\text { Discipline }\end{array}$ & Mass & Charge & $\begin{array}{c}\text { Linear } \\
\text { momentum }\end{array}$ & $\begin{array}{c}\text { Angular } \\
\text { momentum }\end{array}$ & Energy & Entropy & Money \\
\hline Aerospace & $\mathrm{X}$ & $\mathrm{X}$ & $\mathrm{X}$ & $\mathrm{X}$ & $\mathrm{X}$ & $\mathrm{X}$ & $\mathrm{X}$ \\
Agricultural & $\mathrm{X}$ & $\mathrm{X}$ & $\mathrm{X}$ & $\mathrm{X}$ & $\mathrm{X}$ & $\mathrm{X}$ & $\mathrm{X}$ \\
Biomedical & $\mathrm{X}$ & $\mathrm{X}$ & $\mathrm{X}$ & $\mathrm{X}$ & $\mathrm{X}$ & $\mathrm{X}$ & $\mathrm{X}$ \\
Chemical & $\mathrm{X}$ & $\mathrm{X}$ & $\mathrm{X}$ & $\mathrm{X}$ & $\mathrm{X}$ & $\mathrm{X}$ & $\mathrm{X}$ \\
Civil & $\mathrm{X}$ & & $\mathrm{X}$ & $\mathrm{X}$ & & & $\mathrm{X}$ \\
Computer & & $\mathrm{X}$ & & & $\mathrm{X}$ & & $\mathrm{X}$ \\
Electrical & & $\mathrm{X}$ & & & $\mathrm{X}$ & & $\mathrm{X}$ \\
Industrial & $\mathrm{X}$ & $\mathrm{X}$ & $\mathrm{X}$ & $\mathrm{X}$ & $\mathrm{X}$ & & $\mathrm{X}$ \\
Mechanical & $\mathrm{X}$ & $\mathrm{X}$ & $\mathrm{X}$ & $\mathrm{X}$ & $\mathrm{X}$ & $\mathrm{X}$ & $\mathrm{X}$ \\
Nuclear & $\mathrm{X}$ & $\mathrm{X}$ & $\mathrm{X}$ & $\mathrm{X}$ & $\mathrm{X}$ & $\mathrm{X}$ & $\mathrm{X}$ \\
\hline
\end{tabular}

As an integrated curriculum, the FC used engineering accounting to provide the following benefits for students: (a) reinforce student learning, (b) broaden understanding, (c) provide a learning framework, (d) match engineering practice, (e) link disciplines, (f) improve visualization, (g) increase retention, (h) smooth transitions between subjects, (i) establish relevance to engineering career, $(j)$ decrease compartmentalization, $(k)$ connect with learning preferences, (l) avoid haphazard presentation, (m) develop teaming, and (n) improve faculty. Several studies strongly suggested that the Foundation Coalition benefitted all engineering students and hence is suitable for the common curriculum (Fournier-Bonilla, Watson, \& Malavé, 2000); however, most studies of the FC curriculum explored the short-term effects rather than long-term effects on student performance.

\section{Purpose of the Study}

Track A is primarily a problem/project-based learning (PBL) curriculum. In contrast, Track C employs the Foundation Coalition (FC) and is primarily an engineering science-based learning (SBL) curriculum. This study explores the longitudinal impact of PBL vs. SBL curriculum on chemical and petroleum engineering students. To accomplish this, the performance of chemical and petroleum engineering students who took Track $\mathrm{C}$ was compared to other chemical and petroleum engineering students who took Track A. The following research question guided this study: Beyond their first year, what are the longitudinal effects of the FC curriculum on chemical 
and petroleum engineering student performance in terms of (a) graduation status in engineering, (b) time-to-graduation, and (c) cumulative GPA?

\section{Method}

\section{A. Setting}

During each of the 2005 to 2007 school years at the large southwest public university, the firstyear engineering foundation courses consisted of about 60 sections. Three sections of approximately 30 students each were taught in a single classroom, which resulted in a class of less than 100 students. The classroom contained a "problem solving" faculty member drawn from the engineering departments and a graphics faculty member. The problem-solving faculty taught within their track whereas graphics faculty taught across tracks. For example, chemical engineering professors only taught Track $\mathrm{C}$ whereas graphics faculty taught either Tracks A or C. During the 2005 to 2007 school years, chemical and petroleum engineering students selected either Track A or Track $\mathrm{C}$ at the time of the course registration. Ideally, these students would select Track C, which was designed for their major. However, in many cases, students would select Track A for the following reasons: (a) there was a schedule conflict, (b) Track C was full, or (c) they wanted to change their major.

\section{B. Participants}

The target population of this study was first-time-in-college (FTIC) chemical or petroleum engineering students who started their first semester in summer or fall of 2005, 2006, and 2007 at a large southwest public university and attempted to take the first semester engineering foundational course in their first fall semester. The population of 595 newly admitted students included 372 chemical engineering and 223 petroleum engineering majors who took Track A or Track C (FC curriculum)*. Table 3 shows their demographic characteristics in terms of gender, residence, race/ethnicity, and curriculum track by major.

\section{Data Analyses}

The participants' academic activities at the university were tracked in fall $2016^{\dagger}$ (i.e., fall 2005fall 2016) through the data retrieved from the university archive. According to the data, spring 2016 was the semester that showed participants' last academic activities, like graduation from the university. We defined student success in engineering when students graduated in engineering regardless of their entry major. Therefore, participants' graduation status in engineering, time-to-graduation in engineering, and cumulative GPAs were utilized for outcome variables as three indicators of student success in engineering. Here, students' graduation status was categorized into one of three groups: (a) graduation in engineering, (b) graduation in nonengineering, and (c) no graduation. For this quasi-experimental study, Track A students served as a control group and Track $C$ students served as a treatment group for data analyses to explore the impact of FC curriculum (Track C) on student success in engineering.

\footnotetext{
* Students' data from three faculty members of Track C, who modified the FC curriculum, were excluded, which resulted in more numbers of students in Track $\mathrm{A}$ than Track $\mathrm{C}$ for both chemical and petroleum engineering majors.

${ }^{+}$The counting of the semesters was based on the institutional definition in which the summer semesters were counted as fall semesters, so two semesters (i.e., fall and spring) were counted for each school year.
} 
To answer research questions, descriptive statistics were used to identify trends in the data. Then, inferential statistics - such as chi-square tests, independent $t$-tests, and two-way analysis of variances (ANOVAs) - were applied to check statistically significant differences between two groups and among subgroups at the alpha level of .05. All assumptions for inferential statistics (e.g., independent observation, normality, and homogeneity of variance) were checked before the analyses (Field, 2009).

Table 3. Demographic Characteristics of the Participants

\begin{tabular}{lrrrrrr}
\hline & \multicolumn{2}{c}{ Total } & \multicolumn{2}{c}{ Chemical } & \multicolumn{3}{c}{ Petroleum } \\
\hline Category & $N$ & \multicolumn{1}{c}{$n$} & \multicolumn{1}{c}{$n$} & \multicolumn{1}{c}{$n$} \\
\hline Gender & & & & & & \\
$\quad$ Female & 165 & 27.7 & 120 & 32.3 & 45 & 20.2 \\
$\quad$ Male & 430 & 72.3 & 252 & 67.7 & 178 & 79.8 \\
Residence & & & & & & \\
$\quad$ Domestic & 576 & 96.8 & 365 & 98.1 & 211 & 94.6 \\
$\quad$ International & 19 & 3.2 & 7 & 1.9 & 12 & 5.4 \\
Race/Ethnicity & & & & & & \\
$\quad$ Hispanic & 66 & 10.1 & 47 & 12.6 & 19 & 8.5 \\
$\quad$ American Indian or Alaska Native & 2 & 0.3 & 2 & 0.6 & 0 & 0.0 \\
Asian & 28 & 4.7 & 18 & 4.8 & 10 & 4.5 \\
$\quad$ Black & 10 & 1.7 & 6 & 1.6 & 4 & 1.8 \\
$\quad$ Native Hawaiian or other Pacific Islander & 1 & 0.2 & 0 & 0.0 & 1 & 0.4 \\
White & 464 & 78.0 & 288 & 77.4 & 176 & 78.9 \\
$\quad$ Multi-racial & 5 & 8.4 & 3 & 0.8 & 2 & 0.9 \\
Engineering Foundational Course Track & & & & & & \\
$\quad$ A (Traditional curriculum) & 339 & 57.0 & 212 & 57.0 & 127 & 57.0 \\
C (FC curriculum) & 256 & 43.0 & 160 & 43.0 & 96 & 43.0 \\
& & & & & & \\
\hline Total & 595 & 100.0 & 372 & 100.0 & 223 & 100.0 \\
\hline
\end{tabular}

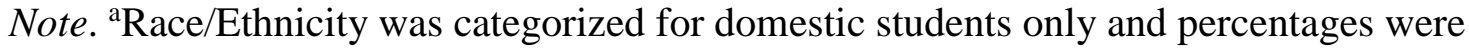
calculated based on the total number of domestic students.

\section{Results}

\section{A. Graduation Status in Engineering}

Figure 1 shows percentages of chemical and petroleum engineering students' graduation status by track. When students who graduated in non-engineering or did not graduate from the university were grouped together, the results of Pearson's chi-square tests showed that there were no significant associations of graduation status with track for each engineering program: $\chi^{2}(1)=$ $0.03, p=.865$ for chemical engineering majors and $\chi^{2}(1)=0.34, p=.562$ for petroleum engineering majors. 


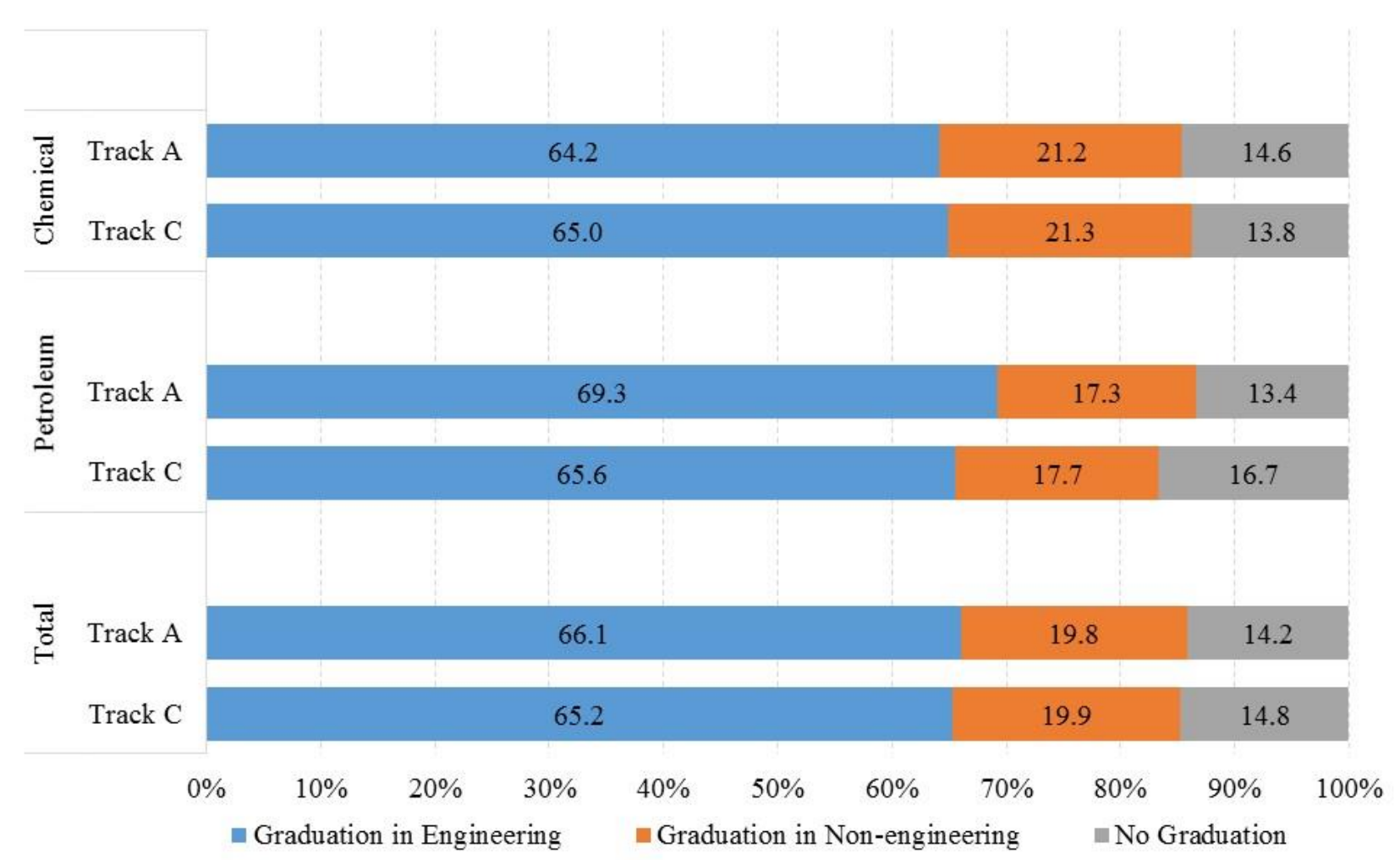

Figure 1. Graduation status of chemical and petroleum engineering students by track.

\section{B. Time-to-Graduation in Engineering}

A two-way analysis of variance (ANOVA) showed that there was a significant main effect of major on the participants' time-to-graduation in engineering: $F(1,387)=4.8, p=.029$, Partial $\eta^{2}$ $=0.012$. However, the effect of track on the participants' time-to-graduation in engineering was not significant with $F(1,387)=2.8, p=.094$, Partial $\eta^{2}=0.007$. In addition, there was no significant interaction effect between track and major with $F(1,387)=1.1, p=.285$, Partial $\eta^{2}=$ 0.003 .

The above results imply that the average time-to-graduation in engineering significantly differs only by major, but not by track. In detail, even though average time-to-graduation of Track C students $(n=167, M=8.98, S D=1.28)$ was slightly shorter than Track A students $(n=224, M=$ $9.16, S D=1.19)$, the difference of 0.18 semesters was not statistically significant. However, chemical engineering students' average time-to-graduation $(n=240, M=9.18, S D=1.28)$ was longer than petroleum engineering students $(n=151, M=8.92, S D=1.13)$, the difference of 0.26 semesters was statistically significant with $t(389)=2.03, p=.043$. 


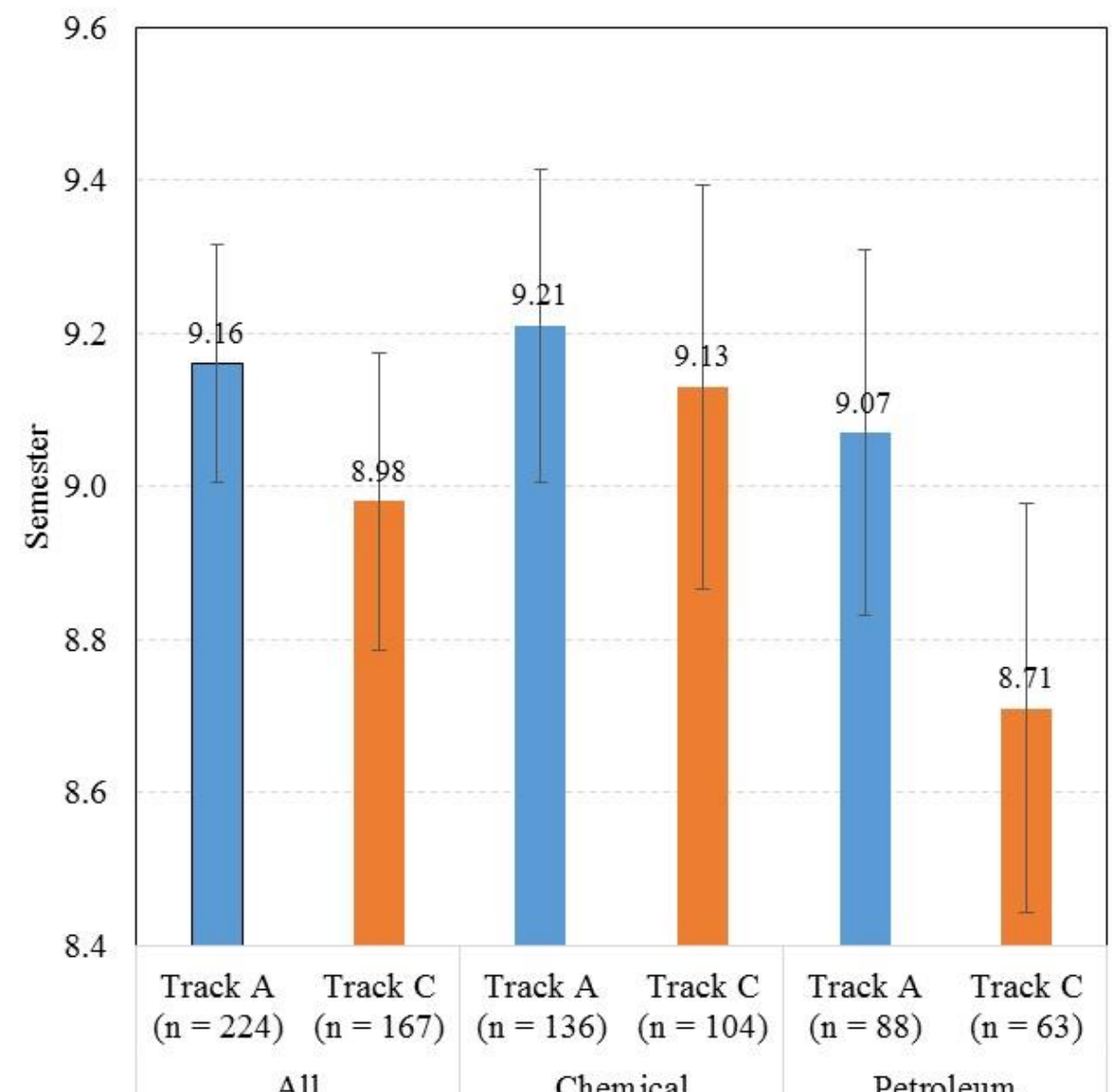

Figure 2. Average time-to-graduation in engineering by major and track (Error bars in $95 \%$ confidence intervals)

\section{Cumulative GPA by the Time of Graduation in Engineering}

A two-way analysis of variance (ANOVA) revealed that there were two significant main effects of track and major each on cumulative GPAs of the participants when they graduated in engineering: $F(1,387)=4.4, p=.036$, Partial $\eta^{2}=.011$ for track and $F(1,387)=9.7, p=.002$, Partial $\eta^{2}=0.024$ for major. However, there was no significant interaction effect between track and major with $F(1,387)=1.3, p=.254$, Partial $\eta^{2}=0.0003$. In detail, average cumulative GPA of Track C students $(n=167, M=3.27, S D=0.46)$ was significantly higher than Track A students $(n=224, M=3.16, S D=0.46)$ with 0.11 point difference, $t(398)=2.47, p=.014$. Furthermore, chemical engineering students' average cumulative GPA $(n=240, M=3.28, S D=$ 0.46 ) was significantly higher than petroleum engineering students $(n=151, M=3.12, S D=$ 0.46 ) with 0.16 point difference, $t(389)=2.99, p=.003$. No interaction effect indicates that Track C students tended to have a higher cumulative GPA than Track A students regardless of their major. Similarly, chemical engineering students tended to have a higher cumulative GPA than petroleum engineering students regardless of their track. Figure 3 delineates the average cumulative GPAs by track and major. 


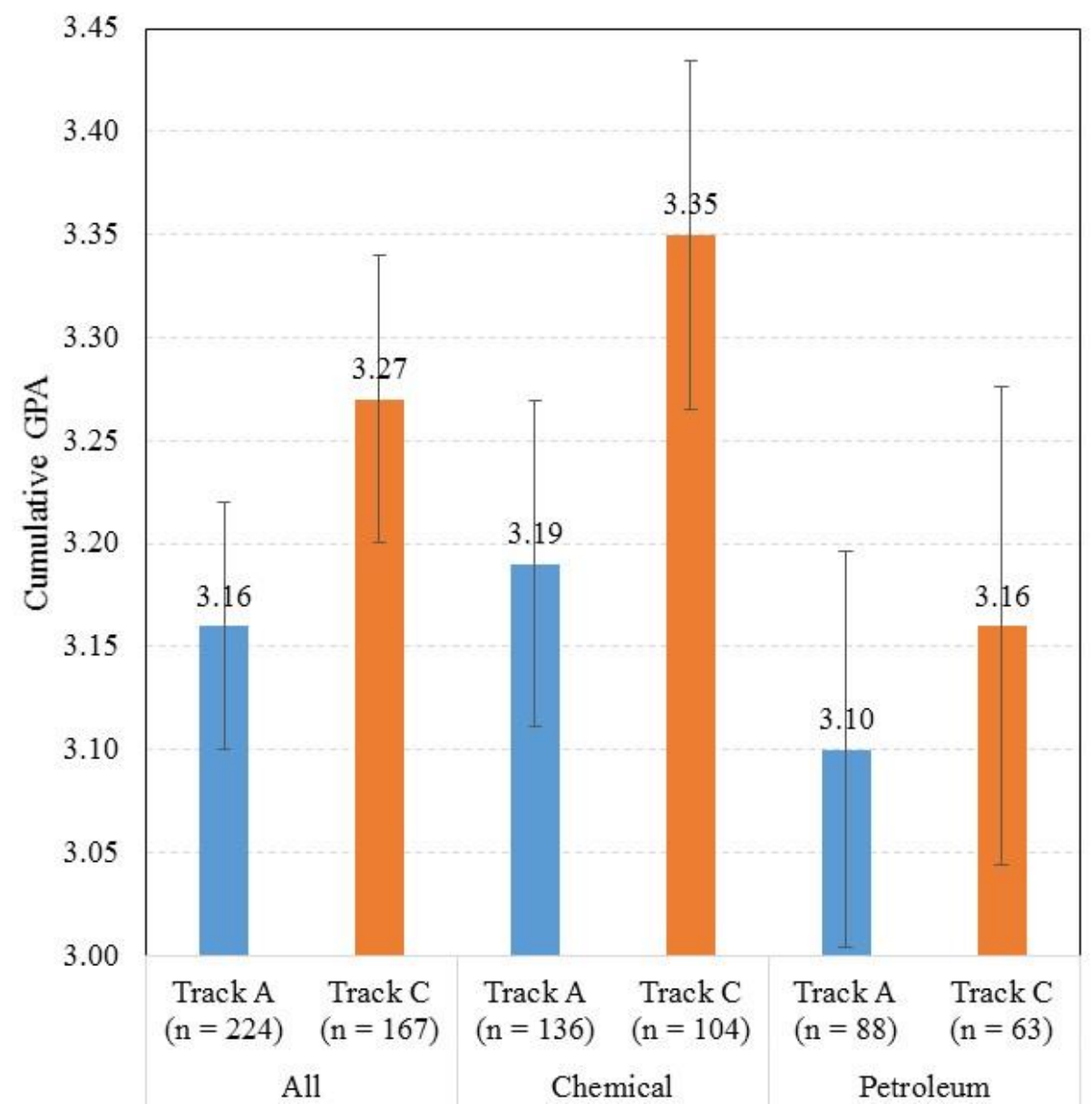

Figure 3. Average cumulative GPAs of participants who graduated in engineering by track and major (Error bars in 95\% confidence intervals)

\section{Discussion}

Regarding graduation status in engineering, the effect of the FC curriculum on chemical and petroleum engineering students was not significant because there was no significant difference between Tracks A and C.

Regarding time-to-graduation in engineering, Track $\mathrm{C}$ students graduated 0.18 semesters quicker than Track A students; however, the differences were not statistically significant. Chemical engineering students' average time-to-graduation (9.18 semesters) was significantly longer than petroleum engineering students (8.92 semesters) regardless of track.

Regarding average cumulative GPAs upon graduation in engineering, Track C students (3.27) were significantly higher than Track A students (3.16). Furthermore, chemical engineering students (3.26) was significantly higher than petroleum engineering students (3.12). In detail, for 
chemical engineering students, Track $C$ (3.35) was 0.16 higher than Track A (3.19). For petroleum engineering students, Track $\mathrm{C}$ (3.16) was 0.06 higher than Track A (3.10).

Although chemical engineering students tended to have higher cumulative GPA than petroleum engineering students, chemical engineering students took longer to graduate than petroleum engineering students. The FC curriculum had no statistically significant impact on students graduating in engineering and time-to-graduation in engineering; however, there was statistically significant impact on cumulative GPA. Track C students showed higher cumulative GPA than Track A students. The effect of the FC curriculum on cumulative GPA was more apparent for chemical engineering students than petroleum engineering students.

One possible explanation for the greater impact of Track $\mathrm{C}$ on chemical engineers is their curriculum has a greater component of engineering science as opposed to engineering practice. The Foundation Coalition is designed to emphasize the fundamentals of engineering science rather than engineering practice, and hence is likely to benefit a curriculum with a heavier emphasis on engineering science.

\section{A. Limitation of the Study and Direction for Future Research}

In this study, we only explored one-semester effects of the FC curriculum on the participants' performance in engineering. Because the FC curriculum was designed for two semesters, there is a need to explore the full academic year effects of the FC curriculum on student performance. Adding this condition will reduce the sample size because not all students who passed the firstsemester engineering foundational course registered for the second-semester course. However, this approach will reveal the full extent of the FC curriculum effects on engineering students' performance.

Although we compared performance between chemical and petroleum engineering students, we acknowledge that each engineering program has a different curriclum and different faculty with their own grading standards; thus, the differences in student performance by major is expected. In addition, in this study, we did not incorporate possible impacts of different instructional strategies by instructors across years because of the limited sample size.

\section{References}

Al-Holou, N., Bilgutay, N. M., Corleto, C., Demel, J. T., Felder, R., Frair, K., Froyd, J. E., Hoit, M., Morgan, J., \& Wells, D. L. (1999). First-year integrated curricula: Design alternatives and examples. Journal of Engineering Education, 88(4), 435-448. doi: 10.1002/j.21689830.1999.tb00471.x

Barrow, D., Bassichis, B., DeBlassie, D., Everett, L., Imbrie, P. K., Whiteacre, M. (1995). An integrated freshman engineering curriculum, why you need it and how to design it. Proceedings of the Frontiers in Education Conference, Atlanta, GA. doi: 10.1109/FIE.1995.483133 
Clark, M. C., Froyd, J., Merton, P., \& Richardson, J. (2003). Evolving models of curricular change: The experience of the Foundation Coalition. Proceedings of the $110^{\text {th }}$ American Society for Engineering Education Annual Conference \& Exposition, Nashville, TN, USA.

Cordes, D., Evans, D., Frair, K., \& Froyd, J. (1999). The NSF Foundation Coalition: The first five tears. Journal of Engineering Education, 88(1), 73-77. doi: 10.1002/j.21689830.1999.tb00414.x

Field, A. (2009). Discovering Statistics Using SPSS. 3rd Ed. London: SAGE Publications Ltd. Fournier-Bonilla, S. D., Watson, K. L., \& Malavé, C. (2000). Quality planning in engineering education: Analysis of alternative implementations of a new first-year curriculum at Texas A\&M University. Journal of Engineering Education, 89(3) 315-322. doi: 10.1002/j.2168-9830.2000.tb00531.x

Fournier-Bonilla, S. D., Watson, K. L., Malavé, C., \& Froyd, J. (2001). Managing curricular change in engineering at Texas A\&M University. International Journal of Engineering Education, 17(3), 222-235.

Froyd, J. E., \& Ohland, M. W. (2005). Integrated engineering curricula. Journal of Engineering Education, 94(1), 147-164. doi: 10.1002/j.2168-9830.2005.tb00835.x

Holtzapple, M., Toback, K., \& Holtzapple, C. (2014). Foundation Coalition: Impact on chemical engineering education at Texas A\&M University 20 years later. Proceedings of the 6th First Year Engineering Experience (FYEE) Conference, College Station, TX, USA.

Morgan, J. R., \& Bolton, R. W. (1998). An integrated first-year engineering curricula. Proceedings of the Frontier in Engineering Conference, Tempe, AZ, USA. 